\title{
Thermophysical characterization of a cardboard emergency kit-house
}

\author{
Dario L. Distefano ${ }^{4 *}$, Antonio Gagliano ${ }^{2}$, Emanuele Naboni $^{3}$, Vincenzo Sapienza ${ }^{1}$, Nicola Timpanaro $^{4}$ \\ ${ }^{1}$ DICAR, University of Catania, viale A. Doria 6, Catania 95125, Italy \\ ${ }^{2}$ DIEEI, University of Catania, Viale A. Doria 6, Catania 95125, Italy \\ ${ }^{3}$ KADK, Philip de Langes Allé 10, 1435, Danmark \\ ${ }^{4}$ Area srl, via Conte di Torino 63, 95131, Italy
}

Corresponding Author Email: agagliano@dii.unict.it

https://doi.org/10.18280/mmep.050306

Received: 6 March 2018

Accepted: 1 June 2018

\section{Keywords:}

architecture, emergency, cardboard, reversibility, repeatability

\begin{abstract}
Recent natural disaster highlighted the need of a form of the emergency-kit house, quickly available to provide shelters for victims of disaster, war refugee or homeless. Usually these requirements are satisfied through tents or containers, which are thermally uncomfortable and induce a sensation of precariousness to people that, were victims of a disaster. An alternative to simple and extemporized solutions is the design of light, evolved and thermally comfortable solutions available before the emergencies and/or in prevision of their occurrence. They are described by victims of a disaster as being thermally uncomfortable and to induce a precariousness felling. This research presents the Archicart Prototype, a Cardboard Architectural system. It is an emergency houses, temporary prefabricated construction and a repeatable system. The prototype provides a quick answers, being easily accessible, mountable, reversible, repeatable and thermally comfortable as described in the paper.

Archicart is a precast building composed of a lightweight and easy to assemble system named PACO (Panels made up of Alveolar Corrugated Cardboard). The system is suitable for the construction of complete housing modules or a portion of buildings, (e.g. walls, partitions, ceiling, roof,). The study verifies thermal performances that are key for the product once installed. The first part concerns the base material's transmittance characterization and the correlation between time, durability and thermal performances decay. Finally the whole system performance are simulated.
\end{abstract}

\section{INTRODUCTION}

It is today recorded an Increased need of emergency-kit houses, quickly ready and able to provide shelters to victims of disaster, war refugee or homeless [1]. To satisfy such urgent requests, thermally uncomfortable tents or containers are often fielded. As an alternative to tents and containers, a system of "emergency architecture" is here proposed. Emergency architecture [2] is a form of ephemeral architecture [4] defined by prefabricated and repeatable construction systems. They are readily available and temporary, aimed at fulfilling immediate residential needs caused by disaster of any type. Emergency architecture is based on the awareness assumption that risks exist, and they are increasingly possible with climate change increased recurrency of extreme climatic events. and the need of quick answers with reversible and repeatable solutions, always available, easy to install by means of selfconstruction [4].

Since decades, designers have been interested in the emergency architecture theme. Here three systems are described in order to relate Archicart to these.

Shigeru Ban largely contributed to the definition of the emergency building (i.e. repeatability, temporary and available), through the well-known series of Paper Log House [5]. Paper tubes (with a diameter of $108 \mathrm{~mm}$ and a thickness of $4 \mathrm{~mm}$ ), are here fastened with wooden clutches to a wooden treading surface, laid on beer cases full of sand sacks. Roofs were made of paper tubes which are lined both outward and inward with a PVC cloth. The gap between the two plastic cloths was ventilated during the warm season via side openings, which improve the summer thermal comfort. The gap is closed in winter thus making the house air tight. Shigeru Ban Paper Log House were used in 1999 in Kaynasli, in the west of Turkey, after an earthquake that caused 20,000 victims and 200,000 evacuees; and 2001 in Bhuj, India, rigtht after an earthquake that caused 20,000 victims and more than 600,000 evacuees.

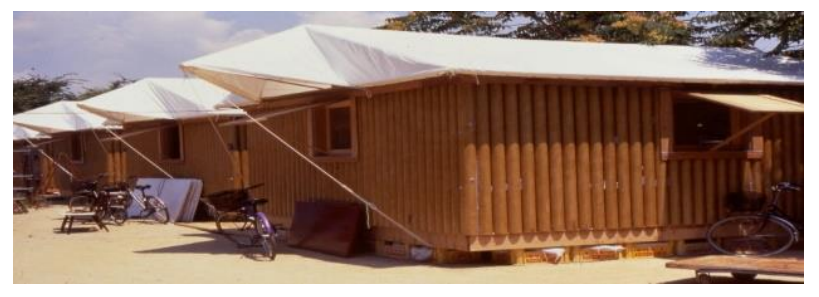

Figure 1. Paper Log House, Shigeru Ban [6]

Ikea's Better Shelter [7] is an emergency shelter. It is the result of a partnership between Ikea foundation and United Nation High Commissiones for Refugees (UNHCR), which started in 2010. The primary module, which Ikea has meant for five guests, has a useful surface of $17.5 \mathrm{~m}^{2}$; and has a double pitch that reaches the height of $2.83 \mathrm{~m}$. The module has 
four windows and a door which can be blocked from both outward and inward. The structure of this housing module is a frame in galvanised steel, and its opaque closing panels are made up of polyolefin polymers, outwardly treated against UV. The lightness and easiness in assembling and dismantling the module make the Better Shelter an alternative solution to the tents of UNHCR. Moreover, Ikea's modules are repeatable, and parts can be easily replaced if damaged. The assembly of a module can be carried by four people in 4 hours, thanks to the precise arrangements of components in the transport case which weights $16.09 \mathrm{~kg}$. The IKEA Better Shelter is a fire- and waterproof module, that last at least for three years due to the degradation of the plastic panels. Since 2015, Better Shelter has delivered more than 17,000 units for humanitarian operations worldwide [8].

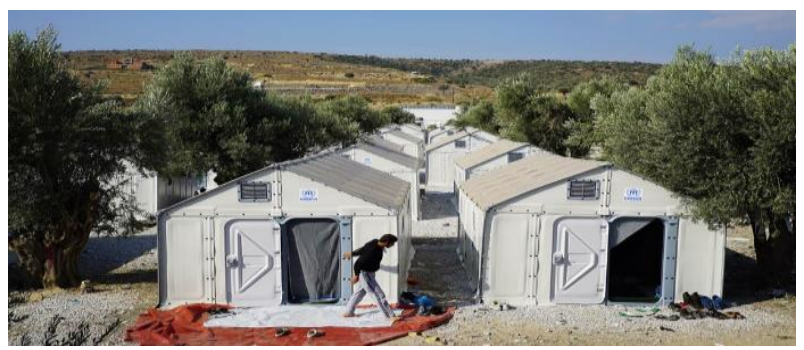

Figure 2. Better Shelter, IKEA Foundation [8]

In case of emergency, the Italian Civil Protection uses emergency houses [9] meant to be temporary shelters for asylum seekers or disaster victims. These prefabricated houses are based on containers sizes, but they are modular and made up of metal panels and insulation. They can be folded (during the transport) and popped-up (during the assembly). The containers represents the most common device used to cope with emergency conditions, being thermically conditioned, with a fast speed of delivery, transport and positioning. They can be easily stored and if maintenance is well exectuted they have shown to be durable. They were used by the Civil Protection agency during the seismic crisis which hit the regions Marche and Umbria in 1997 [9-10].

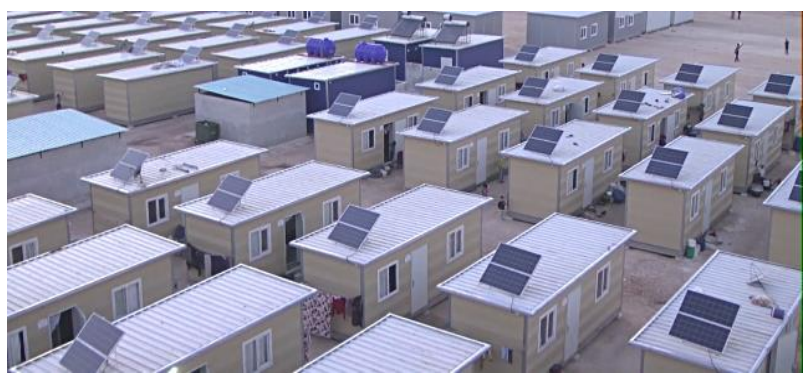

Figure 3. Containers used as temporary houses [11]

The sector of the emergency shelter may constitute an huge opportunity to investigate and characterize new eco-friendly material [12-13], as well for introducing innovative solution in the shelter enevelope [14-15].

A literature study has investigated the suitability of a corrugated fibre board shelter to resist to tropical cyclone wind loadings [16].

In this framework, this paper proposes a novel emergency housing system realised by alveolar corrugated cardboard panels, namely the Archicart (Cardboard Architecture) system [17].
Archicart is a precast system building made of a lightweight and an easy to assemble element named alveolar corrugated cardboard panel, namely PACO. Potentially the system is suitable for the construction of a whole house or for buildings construction subsystems (e.g. walls, partitions, ceiling, roof).

The first part of this study concerns preliminary thermal analysis conducted on the PACO panels. Thus, an Archichart housing for emergency is presented and its main thermal performance are investigated trough dynamic thermal simulations.

\section{MATERIALS AND METHOD}

Archicart PACO is a precast patented construction system based on an evolution of typical use of cardboard boxes.

The concept of PACO includes elongated bands with a rectangular cross-section made of corrugated cardboard (CB) disposed of coaxially with an external which contains some intermediates which in their turn contain some internal ones, fixed together by glue. At upper and lower ends, the panel is closed by two wooden boards equipped with joints for external connections.

Metallic accessories (fastened inside the inner layer of boxing elements, equipped with wooden joints) secure PACOs both together and to the base and roofing.

The stratigraphy of Archicart PACO presents a double layer of triple waves corrugated cardboard both in the external and internal side.

Among these two layers, there is an internal cavity that can host various filling materials, such as cellulose fibre, straw, expanded clay, lime-hemp and others, selectable in relation to each specific application.

Table 1. PACO module

\begin{tabular}{ccc}
\hline & PACO90 & PACO120 \\
\hline dimension $[\mathrm{cm}]$ & $91 \times 10$ & $121 \times 22$ \\
Height $[\mathrm{cm}]$ & 250 & 250 \\
Internal sector & 4 & 5 \\
Type of & Duble wall & Triple wall \\
Cardboard & 30 & 70 \\
Weight $[\mathrm{kg}]$ &
\end{tabular}

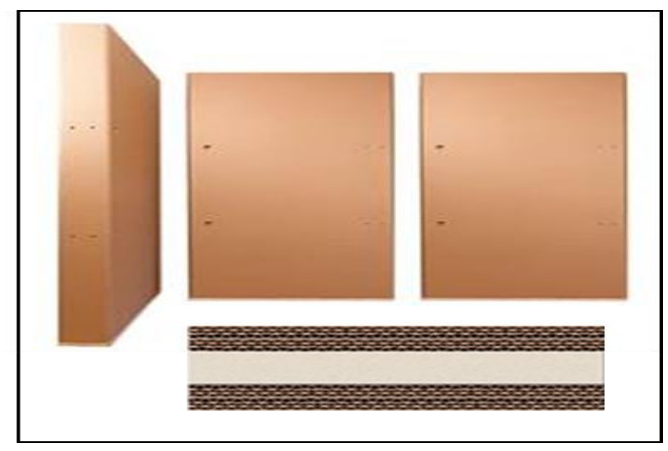

Figure 4. PACO module

This construction method offers a high functional dynamism: it is, indeed, based on dry systems, and on an everchanging design approach that, starting from a basic structure, can become in time a more elaborate building (with regard to users' needs). The spatial shape reproduces, on a larger scale, the same operating principle of boxes that is adopted for the panel-packaging. Panels are installed (through threaded bars), 
either in series or in progression, to create linear and corner walls. This system has the advantage of the modular dimension that enables to adapt forms to real needs of design solutions.

Moreover, PACO panels are easy to transport and to assembly mutually everywhere and in short, to reduce time and costs of the site.

The Archicart PACO samples are composed of a double layer of triple wall corrugated cardboard $28 \mathrm{~mm}$, an internal cavity with variable thick and another triple wall double cardboard layer of $28 \mathrm{~mm}$.

Table 1 and figure 4 shows the characteristics of PACO120 module and PACO90.

\section{HEAT FLOW METERS MEASUREMENTS}

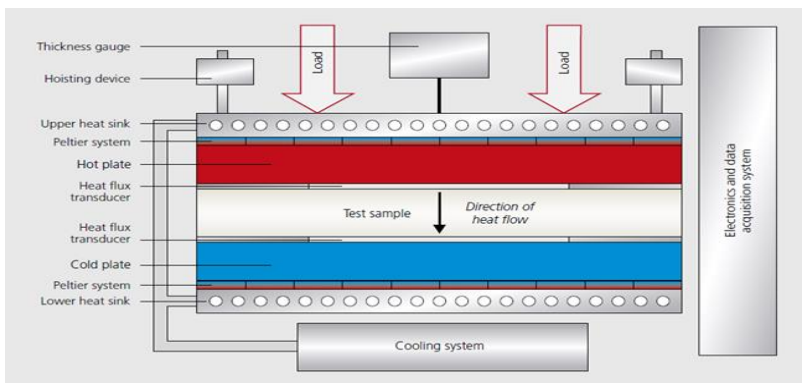

Figure 5. Scheme of the netzsch hfm lambda

One of the objectives of this study is to determine the thermal conductivity, U-value, of Archicart PACO panel when a different type of thermal insulation is placed within the air cavity. This result allows to characterize the thermal performance of the panels and if they satisfy specific requirements.

As well known, thermal conductivity k-value is expressed in $\mathrm{W} / \mathrm{m} \mathrm{K}$ is a measure of the effectiveness of a material to transfer thermal energy.

Measurements of k-value were carried out through the Heat Flow Meters NETZSCH HFM 436 Lambda, which is a calibrated instrument which performs tests according to ASTM C518, ISO 8301, JIS A1412, DIN EN 12664 and DIN EN 12667 [18]. The HFM was placed in a conditioned laboratory at a temperature of $23 \pm 2^{\circ} \mathrm{C}$ and relative humidity $50 \pm 5 \%$, according to the test conditions required by the standard EN 12664: 2002.

A heat flux sensor is a thermopile sensor, consisting of thermocouple junctions arranged uniformly across the sensor surface. Each individual junction generates an electrical voltage, proportional to the difference in temperature across the hot and cold junctions of the thermocouple.

Thermoelectric Peltier elements are used to heat and cool the HFM testing plates

The HFM operates as follows: a sample is positioned between two heating/cooling plates. The upper plate is powered to contact the top of the sample.

One heat flux sensor is integrated into each plate and is used to monitor heat flux $(\mathrm{Q} / \mathrm{A})$, generated due to the difference in temperature $(\Delta \mathrm{T})$ between the top and bottom plate at regular intervals until steady-state heat flux is observed. The composite heat flux is then used to calculate thermal conductivity $(\lambda)$ and thermal resistance (R) according to Fourier's Law.

\subsection{The thermal conductivity of PACO panel}

The thermal conductivity of the PACO panel has been determined with the internal cavity filled with three different thermal insulating materials, as well as only air. Thus the follows filling material were considered:

1. Air

2. $\operatorname{EPS}(\mathrm{k}=0.041 \mathrm{~W} / \mathrm{m} \mathrm{K})$

3. Expanded clay $(\mathrm{k}=0.059 \mathrm{~W} / \mathrm{m} \mathrm{K})$

4. Cellulose fiber $(\mathrm{k}=0.05 \mathrm{~W} / \mathrm{m} \mathrm{K})$

Table 2. Features of the PACO specimens

\begin{tabular}{ccccc}
\hline & $\begin{array}{c}\text { Extern } \\
\text { al layers }\end{array}$ & $\begin{array}{c}\text { EPS } \\
\text { filling }\end{array}$ & $\begin{array}{c}\text { Clay } \\
\text { filling }\end{array}$ & $\begin{array}{c}\text { Cellulo } \\
\text { se filling }\end{array}$ \\
\hline $\begin{array}{c}\text { Size } \\
{[\mathrm{mm}]}\end{array}$ & $300 \times 30$ & $300 \times 3$ & $300 \times 3$ & $300 \times 30$ \\
$\begin{array}{c}\text { Thicknes } \\
\mathrm{s}[\mathrm{mm}]\end{array}$ & $28+28$ & 34 & 34 & 34 \\
$\begin{array}{c}\text { Density } \\
{\left[\mathrm{kg} / \mathrm{m}^{3}\right]} \\
\text { Weight }\end{array}$ & 150 & 10 & 400 & 141 \\
$\begin{array}{c}\mathrm{kg}] \\
\text { Percenta } \\
\text { ge of }\end{array}$ & 0.27 & 0.03 & 1.22 & 0.43 \\
weight [\%] & - & 32.5 & 81.88 & 61.43 \\
\hline
\end{tabular}

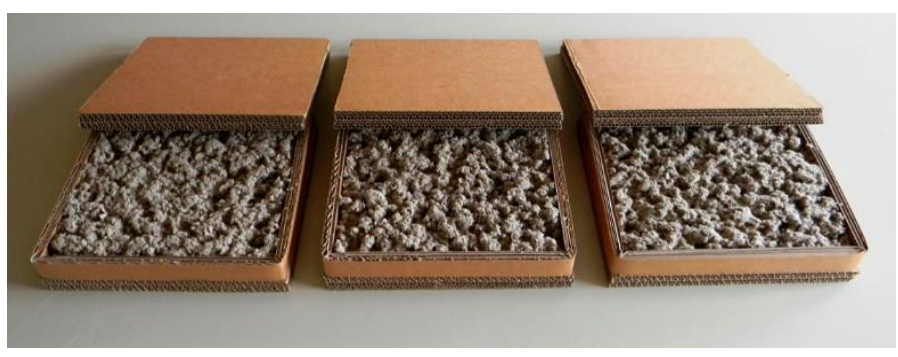

Figure 6. PACO specimen

As the NETZSCH HFM 436 Lambda is able to accept specimen with a maximum dimension of $300 \times 300 \mathrm{~mm}$ and $10 \mathrm{~mm}$ thick, the PACO samples had dimensions 300x300 $\mathrm{x}$ $90 \mathrm{~mm}$ height. Table 2 shows the features of the samples with the different thermal insulation used during the test.

The tests were conducted varying the mean temperatures of the sample, which were 15 and $25^{\circ} \mathrm{c}$, and imposing a constant $\Delta \mathrm{T}$ of $20{ }^{\circ} \mathrm{C}$ between the plates. Thereby, the operating conditions were $5-25^{\circ} \mathrm{C}$ and $15^{\circ}-35^{\circ} \mathrm{C}$

\subsubsection{Measurements results}

Thermal conductivity was measured 5 times for each sample. No significant differences were found among each measurements specimen. Once the coefficients of thermal conductivity $\mathrm{k}$ of the samples were measured, the thermal resistance of the panels has been calculated as $\mathrm{R}_{\mathrm{p} 90, \mathrm{j}}=\mathrm{s} / \mathrm{k}$.

Starting from this result the thermal resistance of the PACO 120 panel, which has a thickness of air gap s= $164 \mathrm{~mm}$ filled with $16.4 \mathrm{~cm}$ of thermal insulation, has been calculated.

The total resistance is calculated summing to the $R_{p 90, j}$ value the thermal resistance provided by the further $130 \mathrm{~mm}$ of thermal insulation $\Delta \mathrm{R}_{\text {isol, } \mathrm{j}}$

$\mathrm{R}_{\mathrm{p} 120-\mathrm{j}}=\mathrm{R}_{\mathrm{sp}-\mathrm{j}}+\Delta \mathrm{R}_{\mathrm{isol}-\mathrm{j}}$

The R-value of the bare PACO system calculated subtracting the R-value of the thermal insulation panels, were 
perfectly convergent, confirming the repeatability of the measurements carried out. Finally the total resistance of the 120/22 PACO panel has been calculated as:

$\mathrm{RT} 120, \mathrm{j}=\mathrm{Rse}+\mathrm{Rp} 120-\mathrm{j}+\mathrm{Rsi}$

The values of $R_{\text {se }}$ and $R_{\text {si }}$ are posed respectively equal to 0.04 and $0.13 \mathrm{~m}^{2} \mathrm{~K} / \mathrm{W}$

Table 3 shows the average values obtained for all the test.

Table 3. Features of the $120 / 22$ PACO panel

\begin{tabular}{ccccc}
\hline & \multicolumn{4}{c}{ Filling materials } \\
\hline & Air & EPS & Clay & Cellulose \\
& & & Fiber \\
Specimen $\mathrm{R}_{\text {sp- }}$ & 1.125 & 2.179 & 1.515 & 1.797 \\
$\Delta \mathrm{R}_{\text {isol, } \mathrm{j}}$ & --- & 3.147 & 2.188 & 2.596 \\
$\mathrm{R}_{\mathrm{p} 120, \mathrm{j}}$ & 1,125 & 5,326 & 3,703 & 4,393 \\
$\mathrm{R}_{\mathrm{T} 120, \mathrm{j}}$ & 1,295 & 5,496 & 3,873 & 4,563 \\
$\mathrm{U}_{\mathrm{T} 120, \mathrm{j}}$ & 0,77 & 0,18 & 0,26 & 0,22 \\
\hline
\end{tabular}

\section{ARCHICART HOUSING-MODULE}

Several surveys have highlighted that refugees as well as asylum seekers state that tents does not provide any privacy and do not offer a chance for basic dignified living. Therefore, following the experience of Shiveru Ban, IKEA and Better Shelter, the Archicart housing system would to provide shelter for the people and temporary home where they could feel safe and warm. Such approach is followed else by the Italian Red Cross, which, in its refugees centers, replaces traditional tents with "Better Shelter" that are more safer and cleaner.

Modular house for emergency, temporary or semipermanent occupation has to be realized with cheap material easy to build and eco-friendly. Thereby the choice of cardboard is successful considering that the cardboard panels are easy to dismantle and the material easily despaired or recycled [19].

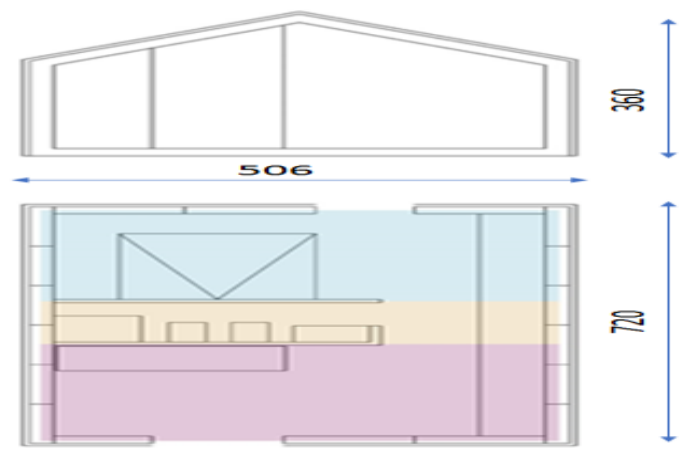

Figure 7. Archicart precasted housing module

Figure 7 depicts the plan of the housing module. It is constituted by three rooms, a living room with the kitchen, the bathroom and a dining room.

The housing modules is designed with the aim to minimize the energy needs $[20,21]$. With this aim, the glazed surface is mainly constituted by a large opening on the south façade that allows exploiting the solar gains during winter period.

In table 4 the main features of the Archicart Lifehouse are compared with that ones of Paper Log House, IkeaBetter Shelter and Container.

It is possible to point out that the Archicart lifehouse has the better performances in terms of thermal insulation.

Moreover, although the PACO system is conceived to be used mainly in the construction of emergency house it

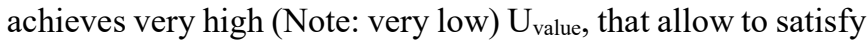
the most stringent constraint of the Italian legislation on the buildings energy efficiency.

Table 4. Comparison of modular houses for emergency

\begin{tabular}{|c|c|c|c|c|}
\hline & Paper Log House & IkeaBetter Shelter & Container CP & Archicart Lifehouse \\
\hline \multicolumn{5}{|c|}{ General } \\
\hline Year & 1995 & 2010 & NA & 2014 \\
\hline Status & Ended & Active & Active & Prototyp \\
\hline Designer & Shigeru Ban & Ikea & NA & Area srl \\
\hline Country & Japan & Sweden & Italy & Italy \\
\hline Size $[\mathrm{cm}]$ & $400 \times 400$ & $332 \times 568$ h 283 & $299 \times 605$ h 279 & $505 \times 720 \mathrm{~h} 360$ \\
\hline \multicolumn{5}{|c|}{ Construction } \\
\hline Production time [days] & NA & NA & $40 \div 15$ & 30 \\
\hline Construction Time & NA & 1 day & 1 day & NA \\
\hline Method & Involved users & Involved users & NA & Involved users \\
\hline Transport & Local oduction & Container or postal package & Container out of standard & Container standard \\
\hline \multicolumn{5}{|c|}{ Materials } \\
\hline Base & Ground & Ground & Ground & Ground \\
\hline Structure & Paper tube & Steel and plastic & Steel & Corrugated Cardboard \\
\hline Glazing & Raw wood & Plastic & Alu and glass & Wood and Low-e glass \\
\hline Systems & none & Heat Pump & Heat Pump & none \\
\hline \multicolumn{5}{|c|}{ Performances $U_{\text {value }}$} \\
\hline$\left[\mathrm{W} / \mathrm{m}^{2} \mathrm{~K}\right]$ Wall & NA & NA & 0.6 & 0.19 \\
\hline Roof & NA & NA & 0.4 & 0.19 \\
\hline $\operatorname{Cost}\left[€ / \mathrm{m}^{2}\right]$ & 118 & NA & NA & 850 \\
\hline
\end{tabular}

\section{THERMAL PERFORMANCE OF ARCHICART HOUSING-MODULE}

\subsection{Dynamic simulation}

The first group of simulations block were conducted considering Mediterranean climatic conditions (Catania Fontanarossa climate file) during both a typical summer week and typical winter week. 
Internal gains were taken into account by considering an occupancy density of 0.05 people $\cdot \mathrm{m}^{-2}$ and a lighting and equipment power density of $4.5 \mathrm{~W} \cdot \mathrm{m}^{-2}$. An air change rate of $0.5 \mathrm{vol} \cdot \mathrm{h}^{-1}$ was used for air quality purposes. The simulation was carried out in free-running conditions to highlight the passive behaviour of the designed housing module. And to verify the design criteria regarding shape, orientation, the thickness of the coating and so on.

Table 5. Features of the housing module

\begin{tabular}{ccc}
\hline Geometric features & $\begin{array}{c}\text { Envelope } \\
\text { component }\end{array}$ & $\begin{array}{c}\mathbf{U} \text {-value } \\
\left(\boldsymbol{W} \cdot \boldsymbol{m}^{-2} \cdot \boldsymbol{K}^{-1}\right)\end{array}$ \\
\hline $\begin{array}{c}\text { Heated gross-volume } \\
(\mathrm{V})=62.7 \mathrm{~m}^{3}\end{array}$ & External walls & 0.229 \\
\hline $\begin{array}{c}\text { Total external surface } \\
(\mathrm{S})=58.1 \mathrm{~m}^{2}\end{array}$ & Pitched roof & 0.229 \\
\hline $\begin{array}{c}\text { Shape factor } \\
(\mathrm{S} / \mathrm{V})=0.93 \mathrm{~m}^{-1}\end{array}$ & Ground floor & 0.229 \\
\hline $\begin{array}{c}\text { Net floor area } \\
\left(\mathrm{S}_{\mathrm{n}}\right)=30.5 \mathrm{~m}^{2}\end{array}$ & Windows & 1.512 \\
\hline
\end{tabular}

\subsection{Simulations results}

As previously mentioned this housing module is characterized by a large door-window placed in the south façade. Therefore, it has to be investigated the influence of an overhang that shade such door-window.

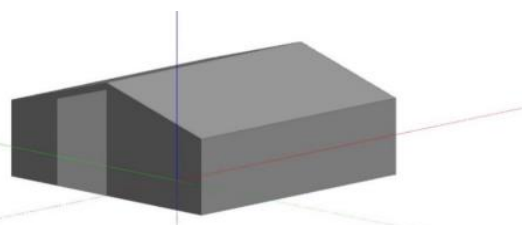

(a)

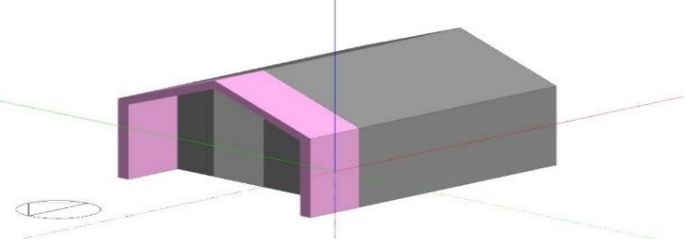

(b)

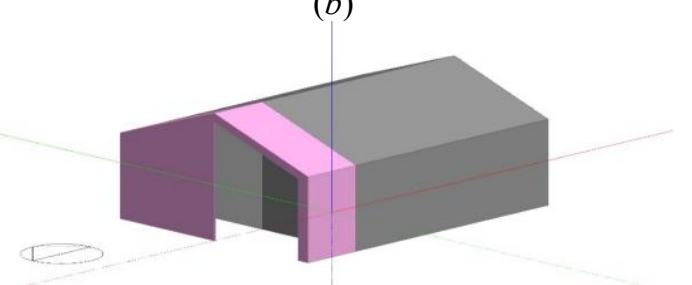

(c)

Figure 8. Archicart precasted housing module

In particular, the effects of a horizontal and vertical shading systems are evaluated. Figure depicts the 3D view of $a$ ) the archicart housing module unshaded, b) with a horizontal overhang (in violet colour) and $c$ ) with both the horizontal overhang and a vertical shading system (in purple colour).

Figure 9 shows the energy fluxes, for two different configuration, through the different component of the building envelope during a winter week, (negative values indicate thermal dispersions). It is possible to highlight, the solar gains provide a great contribute in the energy balance of the building.
Figure 10 depicts the variation of the outdoor, indoor and operative temperature as well as the solar gain trough the windows. The trend of the indoor and operative temperatures are almost equal. This indicate that there are not large temperatures disuniformity within the house.

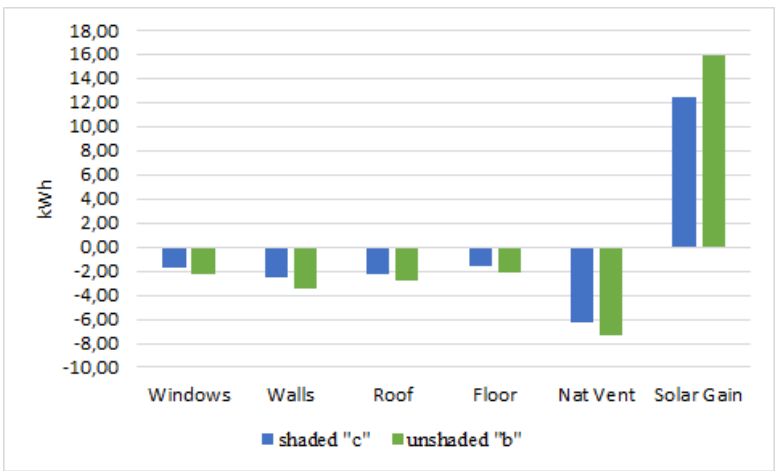

Figure 9. Energy fluxes in a winter week.

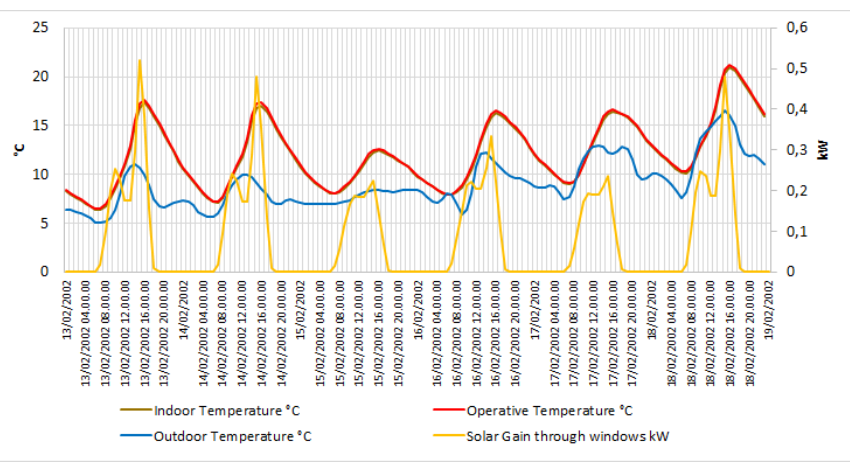

Figure 10. Temperatures and solar gain in a winter week

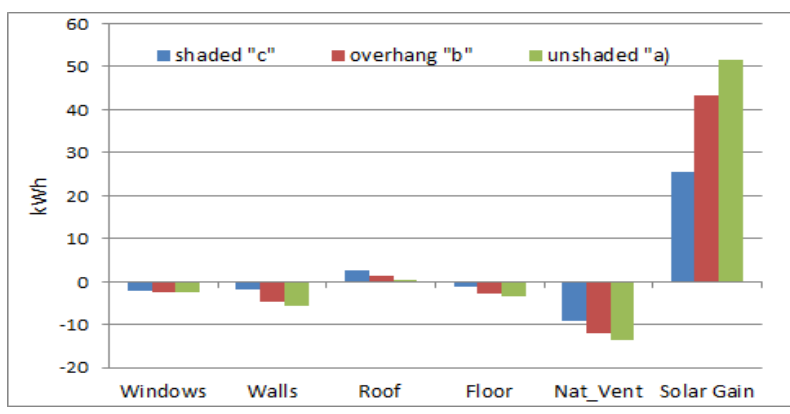

Figure 11. Energy fluxes in a summer week.

Altough the indoor temperature shows wide fluctuations, with an amplitude by $7.0 \div 8.0^{\circ} \mathrm{C}$, during daytime temperatures higher than $15^{\circ}$ are achieved. These results indicate the capability of this temporary house to provide a more than satisfactory protection by the outdoor climate.

Figure 11 shows the energy fluxes through the different component of the building envelope during a summer week. It is possible to point out the huge variation of the solar gain in the three different configuration. The solar gains halved when both the overhang and the sun shadow are applied respect to the unshaded configuration.

As an example, figure 12 shows the variation of the outdoor, indoor and operative temperature as well as the solar gain trough the windows for the shaded configuration ("c"). In summer period, the trend of the indoor and operative temperatures shows some appreciable differences. This 
indicate that there are temperatures disuniformity within the house, which are related to the solar irradiation that pass through the door-windows.

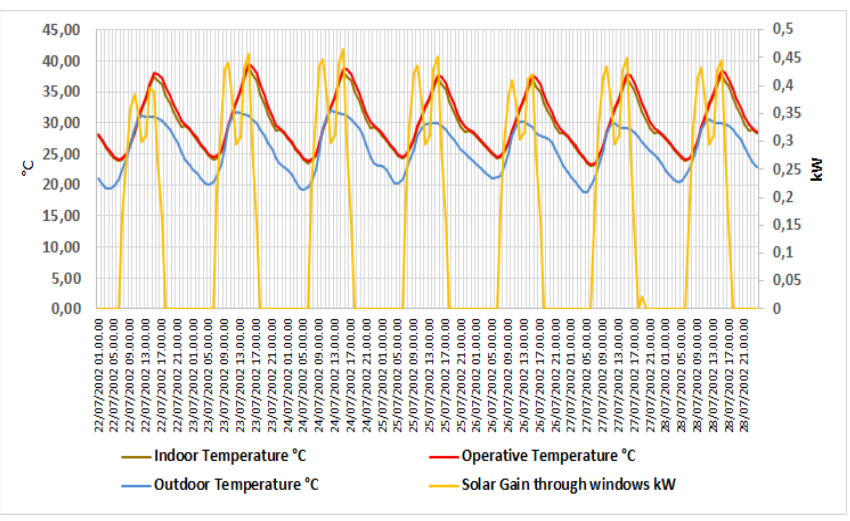

Figure 12. Simulations results

Altough the shadow systems allow to achieve a great diminution of the indoor temperatures, up to $5^{\circ} \mathrm{C}$, the indoor temperature reach intollereable values during the hottest hours of the day. Once again, huge fluctuation of the indoor temperatures, up to $15^{\circ} \mathrm{C}$, are observed.

These results indicate the need to foresee further system to protect the house envelope with the aim to obtain acceptable indoor thermal comfort. A feasible device is the application of a fabric shelter that allow to create a ventilated air gap among the archicart envelope, (façades roof) and the fabric shelter. This solution should replicate a ventilated roof/façade allowing to reduce the solar gain during summer period [22, $23]$.

\section{CONCLUSIONS}

For any shelter for emergency conditions, a comfortable environment plays a central role in the success of the proposed solution. The use of the Archicart PACO system is in this sense could be recommended since it allows to guarantee rather comfortable indoor comfort. However, during the hottest months the Archicart housing module needs to further improvement for reducing the indoor temperatures.

The results of the tests on different samples showed excellent results in terms of conductivity and thermal transmittance. A comparison with other reference technologies sees advantages when it comes to availability of the parent material, environmental and economic sustainability, ease of transport and assembly speed.

Moreover, the Archicart housing module allows to assure privacy and to offer a chance for basic dignified living.

The strength of this technology also lies in the high flexibility of treatment, obtained thanks to the structure of PACO, which allows the internal components to be modified according to the required performances.

The modular construction system and the use of new simulation and prediction software for thermo-physical analysis, pave the way for the optimization processes of the shape that is already underway.

In addition, a first housing prototype made entirely with PACO technology is under construction in the campus of the University of Catania as a result of an academic partnership between the departments of DICAR, DIEEI of the University of catania and Area srl. This in scale prototype will allow comparison of the results of sample and simulation tests shown in this text, with real monitoring along a period of 12 months.

\section{REFERENCES}

[1] UNHCR, Europe Monthly Report. UNHCR. https://reliefweb.int/report/.../unhcr-europemonthly-report, accessed on May 2, 2018.

[2] Distefano DL. (2014). Archicart architettura di cartone. M.S. thesis, University of Catania, Catania.

[3] Unali M. (2010). Architettura effimera. Enciclopedia Treccani XXI Sec. http://www.treccani.it/enciclopedia/architetturaeffimera _\%28XXI-Secolo\%29/, accessed on May 2, 2018.

[4] Falasca C. (2000). Architetture ad assetto variabile, (eds) Alinea ,Firenze.

[5] McQuaid M. (2003) Shigeru Ban. London, UK: Phaidon.

[6] Shigerubanarchitects.

http://www.shigerubanarchitects.com, accessed on May 2,2018

[7] Ikea foundation (2012). Title Better Shelter, A home away from home. http://www.bettershelter.org/wp content/uploads/2015/12/About_Better-Shelter.pdf, accessed on May 2, 2018.

[8] Ikea Foudation (2018). Better Shlter. http://www.bettershelter.org/product/, accessed on May 2, 2018.

[9] Artesi G. (2012). Esercitazione Basilicata. http://www.protezionecivilebasilicata.it/protcivbascma/ files/docs/10/57/40/DOCUMENT_FILE_105740.pdf, accessed on May 2, 2018.

[10] Vv. Aa. (2005). Manuale tecnico per l'allestimento delle aree di ricovero per strutture prefabbricate di protezione civile. Presidenza del Consiglio dei Ministri, Dipartimento della Protezione Civile, Roma. www.protezionecivile.gov.it/resources/cms/.../a2manua le__pubblicazione_modif.pdf. accessed on May 2, 2018.

[11] Emergency live. https://www.emergency-live.com, accessed on May 2, 2018

[12] La Rosa AD, Recca A, Gagliano A, Summerscales J, Latteri A, Cozzo G, Cicala G. (2014). Environmental impacts and thermal insulation performance of innovative composite solutions for building applications. Construction and Building Materials 55: 406-414

[13] Cardinale T, Arleo G, Bernardo F, Feo A, De Fazio P. (2017). Investigations on thermal and mechanical properties of cement mortar with reed and straw fibers" IJHT 35: https://doi.org/10.18280/ijht.35Sp0151

[14] Lassandro P, Di Turi S. (2017). Energy efficiency and resilience against increasing temperatures in summer: the use of PCM and Cool materials in buildings. IJHT 35: S307-S315. https://doi.org/10.18280/ijht.35Sp0142

[15] Bianco V, Diana A, Manca O, Nardini S. (2017). Thermal behavior evaluation of ventilated roof under summer and winter conditions. IJHT 35: S353-S360. https://doi.org/10.18280/ijht.35Sp0142

[16] Distefano DL, Sapienza V. (2014). Archicart Pannelli Alveolari in Cartone Ondulato assemblaggio e metodo. Patent Number CT2014A000006.

[17] Costa MJD, Barlett FM. (2003). Full-scale testing of corrugated fibreboard shelter subjected to staticequivalent wind loads Abbrev. Journal of Wind 
Engineering and Industrial Aerodynamics 91. https://doi.org/10.1016/j/jweia.2003.09.016

[18] Heat Flow Meter - HFM 436 Lambda https://www.netzsch-thermal-analysis.com, accessed on May 2, 2018.

[19] European Database for Corrugated Board Life Cycle Studies 2015. www.fefco.org/sites/default/files/lcareport-2015.pdf, accessed on May 2, 2018.

[20] Nurul HS, Rory P. (2017), Sustainable energy transition, gender and Modernisation in rural Sarawak. Chemical Engineering Transactions 56: 259-264. https://doi.org/10.3303/cet1756044

[21] Nur IA, Rozana Z, Nurul NM, Gamal NAQ, Shaza RS, Siti MS. (2017) Energy efficiency initiatives in a campus building. Chemical Engineering Transactions 56: 1-6. https://doi.org/10.3303/ cet 175600

[22] Baiocco G. (2011). Ricerca per lo sviluppo di un modulo abitativo di emergenza sostenibile a carattere provvisorio. http://dspaceroma3.caspur.it/bitstream/2307/533/1/Baiocco $\% 20 \mathrm{mod}$ uli\%20abitativi\%20provv\%20sost.pdf, accessed on september 24, 2018.

[23] Gagliano A, Nocera F, Aneli S. (2016). Thermodynamic analysis of ventilated façades under different wind conditions in summer period. Energy and Buildings 122: 131-139. https://doi.org/10.1016/j.enbuild.2016.04.035

[24] Gagliano A, Patania F, Nocera F, Ferlito A, Galesi A. (2012).Thermal performance of ventilated roofs during summer period. Energy and Buildings 49: 611-618. https://doi.org/10.1016/j.enbuild.2012.03.007

[25] Bortoloni M, Bottarelli M, Piva S. (2016). Summer thermal performance of ventilated roofs with tiled coverings. J. Phys.: Conf. Ser 796: 012023. https://doi.org/10.1088/1742-6596/796/1/012023 